\title{
correspondence
}

\section{Not a MAFF gaff}

SIR,-The attack by Kenneth Mellanby in your issue of September 16 (p186) quotes recent newspaper interpretations of reports by the Ministry of Agriculture, Fisheries and Food (MAFF) but does not quote from the reports themselves, which are a strictly factual account of our food supply. The MAFF evaluates Britain's food supply at two different levels. The first provides an assessment of the total food available for human consumption in the UK from home production and imports, after deductions have been made for exports and non-food uses; the second (the National Food Survey) provides an assessment of food bought at the retail level by different types of household. Professor Mellanby's article appears to be based on newspaper comments on the former, which was published in Trade and Industry on August 27 of this year (p596).

Value judgements are not appropriate to these published accounts, and the MAFF nowhere suggests in them that "Britons eat too little food of any kind", or that "the quality of food consumed shows a steady decline", or that "the consumption of more animal protein leads to better nourishment". Rather, it is clear that an average energy value of $12.16 \mathrm{MJ}(2,910 \mathrm{kcal}-$ orie) per person per day is substantially more, not less, than any recommendation from the United Nations' Food and Agriculture Organisation. Furthermore, the most recent report of the UK National Food Survey Committee shows that the food purchases of British households provide substantially more of almost every major nutrient than is recommended by the UK Department of Health and Social Security, and that the nutritional quality (estimated as amounts of nutrients per 1,000 kcalorie) is in several respects increasing.

\section{H. C. Pereira}

Chief Scientist,

Ministry of Agriculture, Fisheries and Food,

Whitehall Place,

London SW1A 2HH, UK

\section{Tobacco substitutes}

SIR,-Tobacco substitutes cannot be so neatly classified as the article by Allan Piper implies (Nature, September 2, p2); nor is it relevant, as the article might also imply, to predict the toxicological characteristics of tobacco substitutes from smoke chemistry data.

Tobacco itself, of course, has both 'organic' and 'inorganic' components. Both NSM and Cytrel, which are currently the subjects of submissions to the UK Hunter Committee, are 'organic' to the extent that each contains cellulose derivatives as combustible fuels, and glycerol as a humectant; and both these tobacco supplements are also 'inorganic' to the extent that each contains a proportion of mineral fillers.

Both NSM and Cytrel produce smoke, the composition of which differs considerably from that of tobacco smoke; and to rely upon the chemical composition of smoke to predict toxicological characteristics, as Piper's article can imply, is unwise. The fact is, and there is ample evidence for this from many other aspects of toxicology, that our understanding of the biological effects of chemical compounds, acting alone or in combination, is quite insufficient to allow any such prediction to be made. Instead, reliance must be placed primarily upon a comparison with tobacco in terms of tests which provide direct measurements of biological activity relevant to diseases associated with cigarette smoking, and upon other toxicological tests to afford an acceptable assurance in respect of risks to health not associated with cigarette smoking. This need is very clearly recognised in the first report of the Independent Scientific Committee on Smoking and Health. The results of such direct comparisons using NSM have been most reassuring.

$$
\text { T. R. C. Reynolns }
$$

New Smoking Materials Limited, Wilmslow, Cheshire SK9 1QB, UK

\section{Limiting parameters}

SiR,-During the past decade or more, articles published in scientific journals have been increasingly disfigured by the use of the word 'parameters' to include any variables that can be measured (Nature, September 16, p387). This practice, though discouraged by one learned society (Medical Research Society), now seems to be blessed by the Shorter Oxford English Dictionary (OED)-(see Addenda p2649). The added meaning is "a distinguishing or defining characteristic or feature esp. one that may be measured or quantified, 1962" that is, a variable.
The 1964 edition of the Shorter OED gives several meanings of the word 'parameter' specific to certain disciplines such as mathematics, astronomy and crystallography, but defines its general meaning as "a quantity which is constant (as distinct from the ordinary variables) in a particular case considered, but which varies in different cases: esp. a constant occurring in the equation of a curve or surface, by the variation of which the equation is made to represent a family of such curves or surfaces, 1852". This definition seems to me (with relics of schoolboy Greek to conform with $\pi \alpha \rho \alpha \mu \varepsilon \tau \rho \varepsilon \omega$, "to measure one thing by another, to compare, Plato" (An Intermediate Green-English Lexicon, Liddell and Scott, 1955).

Oxford lexicographers may exculpate themselves with the defence that they merely record current usage in both spoken and written form (even though it tends to perpetuate a nonsense that a parameter may be sometimes a constant, at others a variable). But do editors of scientific publications, which require exactitude for permanent records, need to be so fickle? If the Editor of Nature were to insist that in his journal the word 'parameter' in the general sense shall have the 1852 meaning, would not editors of all journals less widely read soon follow suit, to the great benefit of all discerning readers?

This clarification of the current fog would not resolve the underlying difficulty that there is a persistent demand for a word to embrace the measurable and estimable quantitics of a system, for which the word 'parameters' is now fashionably used. If a factor is measurable, there is little harm in referring to it as 'a measurable'; but if it is a derived number like the constants, $a$ or $b$ (parameters) of the equation of direct proportionality of the two variables $x$ and $y(y=a+b x)$ it is not directly but only indirectly 'a measurable'. In the collective sense measurables plus estimables are 'quantifiables' or 'quantities', or 'numerables'.

J. F. LoutiT

Medical Research Council,

Harwell, Didcot, Oxford, UK

The Editor of Nature welcomes all correspondence. Letters should be kept as brief as possible. 